\title{
PROTETORES SOLARES
}

\section{Juliana Flor e Marian Rosaly Davolos}

Instituto de Química, Universidade Estadual Paulista, CP 355, 14801-970 Araraquara - SP, Brasil

Marcos Antonio Correa

Faculdade de Ciências Farmacêuticas, Universidade Estadual Paulista, CP 502, 14801-902 Araraquara - SP, Brasil

Recebido em 31/3/05; aceito em 7/2/06; publicado na web em 30/8/06

\begin{abstract}
SUNSCREENS. Health problems related to UV radiation can be minimized by the appropriate use of sunscreens. Different kinds of sunscreens are reported in the literature, even though there is a misleading denomination among them and few discussions are presented about how they work. This paper describes some important aspects in order to understand sunscreen phenomena such as: solar radiation effect, type of solar filters, protection mechanism, formulations and solar protection factor (SPF). Moreover the importance of Chemistry and the interdisciplinary studies related to sunscreens and cosmetic researches are emphasized.
\end{abstract}

Keywords: sunscreens; SPF; UV-absorbers.

\section{INTRODUÇÃO}

A necessidade do uso de protetores solares, também denominados fotoprotetores, é uma realidade indiscutível e acompanhando esta tendência o mercado oferece sua resposta. Estima-se que em 1992 o mercado nacional de protetores solares tenha comercializado $650 \mathrm{t}$ de produtos $^{1}$. Dez anos mais tarde, em 2002, este mesmo mercado atingiu a produção de aproximadamente $4.200 \mathrm{t}^{1}$. Tais números não somente revelam a crescente importância deste segmento, como também sugerem o enorme potencial de crescimento para os próximos anos. Reforça esta potencialidade o fato de o mercado global ter movimentado, em 2002, US\$3,45 bilhões e que, desse total, a América Latina tenha contribuído com apenas US $\$ 247,6$ milhões ${ }^{1}$. Além do aspecto mercadológico, o grande enfoque para este setor baseia-se indiscutivelmente na real necessidade da fotoproteção. Neste sentido, e com o objetivo de oferecer preparações com maior eficácia (produtos com melhor eficiência de proteção, maior estabilidade química e mais acessíveis à população), o segmento tem exigido dos formuladores grande aperfeiçoamento técnico e dos fabricantes de matéria-prima, pesquisa e desenvolvimento de novos filtros solares. Além disto, é necessária uma melhor compreensão do comportamento físico-químico tanto das novas quanto das tradicionais moléculas utilizadas como filtros solares. Neste artigo são apresentados alguns itens importantes para o entendimento dos fenômenos que envolvem protetores solares, tais como efeitos da radiação solar, filtros solares orgânicos e inorgânicos e mecanismos de proteção, formulações e fator de proteção.

\section{EFEITOS DA RADIAÇÃO SOLAR}

O Sol é essencial para a vida na Terra e seus efeitos sobre o homem dependem das características individuais da pele exposta, intensidade, frequiência e tempo de exposição, que por sua vez dependem da localização geográfica, estação do ano, período do dia e condição climática. Estes efeitos trazem benefícios ao ser humano, como sensação de bem-estar físico e mental, estímulo à produção de melanina com conseqüente bronzeamento da pele, trata-

*e-mail: davolos@iq.unesp.br mento de icterícia (cor amarela da pele e do branco dos olhos de bebês, causada pelo excesso de bilirrubina no sangue), etc. Porém, a radiação solar também pode causar prejuízos ao organismo, caso não se tome os devidos cuidados quanto à dose de radiação solar recebida ${ }^{2}$.

O espectro solar que atinge a superfície terrestre é formado predominantemente por radiações ultravioletas (100-400 nm), visíveis (400-800 nm) e infravermelhas (acima de $800 \mathrm{~nm}$ ). Nosso organismo percebe a presença destas radiações do espectro solar de diferentes formas. A radiação infravermelha (IV) é percebida sob a forma de calor, a radiação visível (Vis) através das diferentes cores detectadas pelo sistema óptico e a radiação ultravioleta (UV) através de reações fotoquímicas. Tais reações podem estimular a produção de melanina cuja manifestação é visível sob a forma de bronzeamento da pele, ou pode levar desde a produção de simples inflamações até graves queimaduras. Também, há a possibilidade de ocorrerem mutações genéticas e comportamentos anormais das células, cuja freqüência tem aumentado nos últimos anos ${ }^{3}$.

A energia da radiação solar aumenta com a redução do comprimento de onda, assim a radiação UV é a de menor comprimento de onda e, conseqüentemente, a mais energética, ou seja, a mais propensa a induzir reações fotoquímicas. Outra consideração importante diz respeito à capacidade desta radiação permear a estrutura da pele. A radiação UV de energia menor penetra mais profundamente na pele e, ao atingir a derme, é responsável pelo fotoenvelhecimento ${ }^{3}$.

A faixa da radiação UV (100 a $400 \mathrm{~nm})^{4}$ pode ser dividida em três partes:

\section{UVA (320 a $400 \mathrm{~nm})$}

Freqüentemente a radiação UVA não causa eritema. Dependendo da pele e da intensidade da radiação recebida, o eritema causado é mínimo. Quando comparada à radiação UVB, sua capacidade em induzir eritema na pele humana é aproximadamente mil vezes menor, porém penetra mais profundamente na derme. Induz pigmentação da pele promovendo o bronzeamento por meio do escurecimento da melanina pela fotoxidação da leucomelanina, localizada nas células das camadas externas da epiderme². É mais abundante que a radiação UVB na superfície terrestre (UVA 95\%, UVB 5\%). Histologicamente, causa danos ao sistema vascular pe- 
riférico e induz o câncer de pele, dependendo do tipo de pele e do tempo, freqüência e intensidade de exposição ${ }^{5,6}$. A radiação UVA também pode agir de maneira indireta, formando radicais livres ${ }^{3}$.

\section{UVB (280 a $320 \mathrm{~nm})$}

A radiação UVB atinge toda a superfície terrestre após atravessar a atmosfera. Possui alta energia e, com grande freqüência, ocasiona queimaduras solares. Também induz o bronzeamento da pele, sendo responsável pela transformação do ergosterol epidérmico em vitamina $\mathrm{D}$, e causa o envelhecimento precoce das células ${ }^{5,6}$. A exposição freqüente e intensa à radiação UVB pode causar lesões no DNA, além de suprimir a resposta imunológica da pele. Desta forma, além de aumentar o risco de mutações fatais, manifestado sob a forma de câncer de pele, sua atividade reduz a chance de uma célula maligna ser reconhecida e destruída pelo organismo ${ }^{7}$.

\section{UVC (100 a $280 \mathrm{~nm})$}

A radiação UVC é portadora de elevadas energias, característica que a torna extremamente lesiva aos seres vivos ${ }^{6,7}$.

Devido à absorção pelo oxigênio e pelo ozônio na estratosfera, nenhuma radiação UVC, e pequena fração de UVB, chega à superfície da Terra. Devido a fatores ambientais, a redução na camada de ozônio tem levado a um aumento da radiação UVB na superfície da Terra, ocasionando maior incidência de queimaduras e, conseqüentemente, câncer de pele ${ }^{8}$. A Austrália vem tendo grandes problemas com os níveis de radiação ultravioleta devido a sua localização e à destruição em larga escala da camada de ozônio na Antártica $^{8}$, provocando maior incidência de câncer de pele ${ }^{9,10}$. Fatores como estes justificam a preocupação com a destruição da camada de ozônio.

Os perigos à saúde, relacionados à radiação UV, podem ser minimizados pelo emprego de protetores solares ${ }^{11}$, os quais estão no mercado há mais de 60 anos. Inicialmente, eles foram desenvolvidos para proteger a pele contra queimaduras do sol, isto é, preferencialmente contra a radiação UVB, permitindo bronzeamento por meio de UVA. Com o crescente conhecimento a respeito de UVA, ficou evidente que a pele precisaria ser protegida de toda faixa UVA/UVB ${ }^{12,13}$, para reduzir o risco de câncer de pele causado por exposição ao sol. Em consequiência, nasceu um novo conceito: um protetor solar eficiente deve prevenir não apenas uma possível queimadura, mas também reduzir o acúmulo de todas as lesões induzidas pela radiação UV, que podem aumentar o risco de alterações fatais ${ }^{14}$.

Proteger a pele frente às manifestações produzidas pela radiação UV significa converter a energia desta em outra forma de energia e ter garantias de que esta outra forma não seja prejudicial à pele. Os filtros UV empregados em formulações de protetores solares necessitam ser química e fotoquimicamente inertes ${ }^{3}$.

\section{TIPOS DE FILTROS SOLARES E MECANISMOS DE PROTEÇÃO}

Existem duas classes de filtros solares: orgânicos e inorgânicos, classificados rotineira e respectivamente como filtros de efeito químico (filtros químicos) e filtros de efeito físico (filtros físicos) ${ }^{15}$. Tal classificação apresenta apenas um caráter comercial e necessita ser reavaliada. Os processos de absorção e reflexão de radiação são considerados fenômenos físicos desde que não haja uma reação química. Assim, uma molécula absorvedora de radiação UV não necessariamente deve ser chamada de filtro químico. A classificação de filtros orgânicos e inorgânicos torna-se mais sensata, uma vez que nos filtros orgânicos temos a presença de compostos orgânicos e nos inorgânicos temos a presença de óxidos metálicos. Geralmente, os compostos orgânicos protegem a pele pela absorção da radiação e os inorgânicos, pela reflexão da radiação. Existem no mercado, atualmente, filtros orgânicos que além de absorver, refletem a radiação UV. A Ciba Especialidades Químicas disponibilizou ao mercado o "Methylene Bis-Benzotriazolyl Tetramethylbutyl-phenol - MBBT", Tinossob ${ }^{\circledR}$ M, que, mesmo sendo orgânico, apresenta a capacidade de reflexão e dispersão da radiação, além da capacidade de absorção das radiações UV, comportando-se, desta forma, como um filtro também de efeito físico. Ressalta-se que os fenômenos reflexão e espalhamento dependem do tamanho de partículas do filtro inorgânico, entre outros fatores e não do fato de ser composto orgânico ou inorgânico.

\section{Filtros orgânicos}

Os filtros orgânicos são formados por moléculas orgânicas capazes de absorver a radiação UV (alta energia) e transformá-la em radiações com energias menores e inofensivas ao ser humano. Estas moléculas são, essencialmente, compostos aromáticos com grupos carboxílicos. No geral, apresentam um grupo doador de elétrons, como uma amina ou um grupo metoxila, na posição orto ou para do anel aromático. Ao absorver a radiação UV, os elétrons situados no orbital $\pi$ HOMO (orbital molecular preenchido de mais alta energia) são excitados para orbital $\pi^{*}$ LUMO (orbital molecular vazio de mais baixa energia) e, ao retornarem para o estado inicial, o excesso de energia é liberado em forma de calor. As transições eletrônicas que estão envolvidas durante a absorção da luz UV ocorrem entre a diferença de energia HOMO - LUMO.

Diversos são os filtros solares orgânicos presentes no mercado. Na Tabela 1 estão apresentados alguns deles com suas propriedades físicas, químicas, características UV e toxicidade ${ }^{16}$.

Nas Figuras de 1 a 3 são apresentados três filtros orgânicos juntamente com suas fórmulas estruturais e seus espectros de absorção.

Observando os espectros de absorção obtidos pela solubilização dos filtros em etanol, nota-se uma grande diferença na região de absorção. No caso do ácido p-aminobenzóico (PABA) observa-se o máximo de absorção em $283 \mathrm{~nm}$, sendo que o espectro compreende parte da região UVC e toda a região UVB. Já o seu derivado, OctildimetilPABA, apresenta deslocamento do máximo de absorção para $311 \mathrm{~nm}$ e o espectro de absorção compreende apenas a região UVB. No caso do Butil Metoxi-dibenzoil-metano observase o máximo de absorção em $358 \mathrm{~nm}$, sendo que o espectro cobre toda a região UVA.

Para entendermos essas diferenças nos máximos de absorção podemos utilizar de maneira simplificada a teoria de orbitais moleculares (TOM) $)^{17,18}$. Na Figura 4a apresenta-se uma ilustração simplificada dos orbitais moleculares do benzeno. Inserindo no anel uma espécie doadora de elétrons, aumenta-se a possibilidade de ressonância e a estabilidade do anel. Sendo mais estável, a energia dos orbitais ligantes diminui e, conseqüentemente, a dos antiligantes aumenta, elevando assim a diferença de energia entre os orbitais HOMO e LUMO, Figura 4b. Por outro lado, a adição de uma espécie receptora de elétrons ao anel aromático diminui a estabilidade do sistema. Desta forma, a energia dos orbitais ligantes aumenta e a dos antiligantes diminui, reduzindo a diferença de energia entre os orbitais HOMO e LUMO ${ }^{19}$, Figura 4c.

Considerando o que foi relatado e as estruturas dos filtros, observa-se que na estrutura eletrônica do PABA estão presentes o grupo doador de elétrons $\mathrm{NH}_{2}$ e o grupo receptor de elétrons $\mathrm{COOH}$ e no caso do OctildimetilPABA tem-se o grupo doador de elétrons $\left(\mathrm{CH}_{3}\right)_{2} \mathrm{~N}$ e o grupo receptor de elétrons COOR. Já no Butil Metoxi- 
Tabela 1. Características de alguns filtros orgânicos utilizados em protetores solares. Adaptada da ref. 16

\begin{tabular}{|c|c|c|c|c|c|}
\hline Filtro nome INCI & Benzofenona 3 & $\begin{array}{l}\text { Butil-Metoxi- } \\
\text { dibenzoil-metano }\end{array}$ & $\begin{array}{l}\text { Octildimetil } \\
\text { PABA }\end{array}$ & PABA & $\begin{array}{l}\text { Gliceril } \\
\text { PABA }\end{array}$ \\
\hline Filtro nome IUPAC & $\begin{array}{l}\text { (2-hidroxi-4- } \\
\text { metoxi-fenila) } \\
\text { fenil-metanona }\end{array}$ & $\begin{array}{l}\text { 4-4-butil-4'- } \\
\text { metóxi dibenzoil- } \\
\text { metano-ona }\end{array}$ & $\begin{array}{l}\text { p-dimetil- } \\
\text { aminobenzoa- } \\
\text { to de 2-etil- } \\
\text { hexila }\end{array}$ & $\begin{array}{c}\text { ácido p- } \\
\text { aminobenzóico }\end{array}$ & $\begin{array}{c}\text { 1-(4-aminobenzo- } \\
\text { ato) de } 1,2,3 \\
\text { propanotriol }\end{array}$ \\
\hline Massa Molar / $\mathrm{g} \mathrm{mol}^{-1}$ & 228 & 310 & 277 & 137 & 211 \\
\hline Ponto de Fusão $/{ }^{\circ} \mathrm{C}$ & $62-64$ & $83 \pm 2$ & - & $186-189$ & $110 \pm 2$ \\
\hline Solubilidade: solúvel em & $\begin{array}{c}\text { ACETO, AE, } \\
\text { AcET, AI }\end{array}$ & ADIP, MIP & $\begin{array}{c}\text { AE, AI, MIP, } \\
\text { OM }\end{array}$ & $\begin{array}{c}\mathrm{A}, \mathrm{AE}, \mathrm{AcEt}, \\
\mathrm{AI}\end{array}$ & $\begin{array}{l}\mathrm{G}, \mathrm{AE}, \mathrm{AI}, \\
\quad \mathrm{PPG}\end{array}$ \\
\hline Solubilidade: insolúvel em & $\mathrm{A}, \mathrm{OM}$ & $\begin{array}{c}\mathrm{A}, \mathrm{G}, \mathrm{AE}, \mathrm{AI} \\
\mathrm{OM}, \mathrm{ADIP}\end{array}$ & $A, G$ & G, OM, MIP & $\mathrm{A}, \mathrm{OM}$ \\
\hline$\lambda_{\text {MÁx }}$ absorção / nm & 288 e 325 & 358 & 311 & 283 & 297 \\
\hline Toxicidade $\mathrm{DL}_{50}$ (oral) & $>5 \mathrm{~g} / \mathrm{kg}$ & $>5 \mathrm{~g} / \mathrm{kg}$ & $>5 \mathrm{~g} / \mathrm{kg}$ & $>5 \mathrm{~g} / \mathrm{kg}$ & $>5 \mathrm{~g} / \mathrm{kg}$ \\
\hline Regulamentação Brasil & $10 \%$ & $5 \%$ & $8 \%$ & $\begin{array}{l}15 \% \text { expresso } \\
\text { como ácido }\end{array}$ & $5 \%$ \\
\hline
\end{tabular}

INCI - "International Nomenclature of the Cosmetic Ingredients"; IUPAC - União Internacional de Química Pura e Aplicada; A - água, AcEt - acetato de etila, ACETO - acetona, ADIP - adipato de isopropila, AE - álcool etílico, AI - álcool isopropílico, G - glicerina, MIP - miristato de isopropila, $\mathrm{OM}$ - óleo mineral; $\mathrm{DL}_{50}$ - dose letal oral e Regulamentação Brasil - proporção em massa máxima permitida.

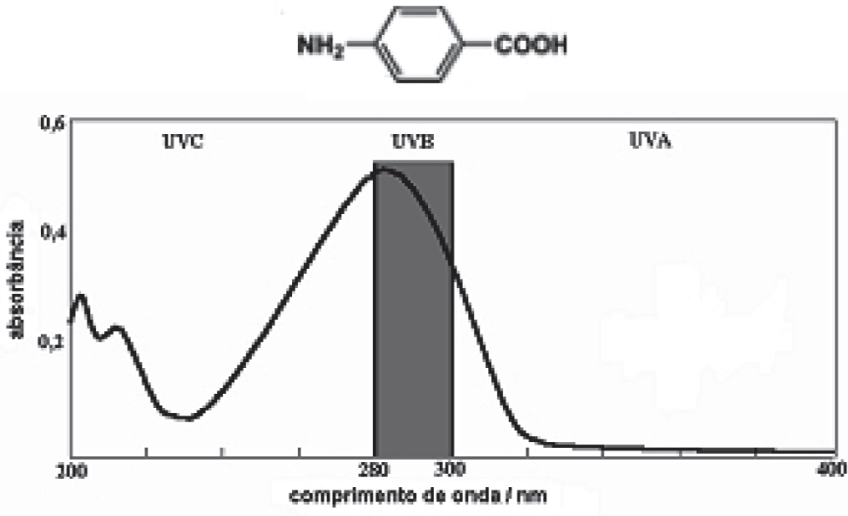

Figura 1. Fórmula estrutural e espectro de absorção do filtro ácido paminobenzóico (PABA), 5,09 $\mathrm{mg} \mathrm{L}^{-1}$ em etanol. Adaptada da ref. 16

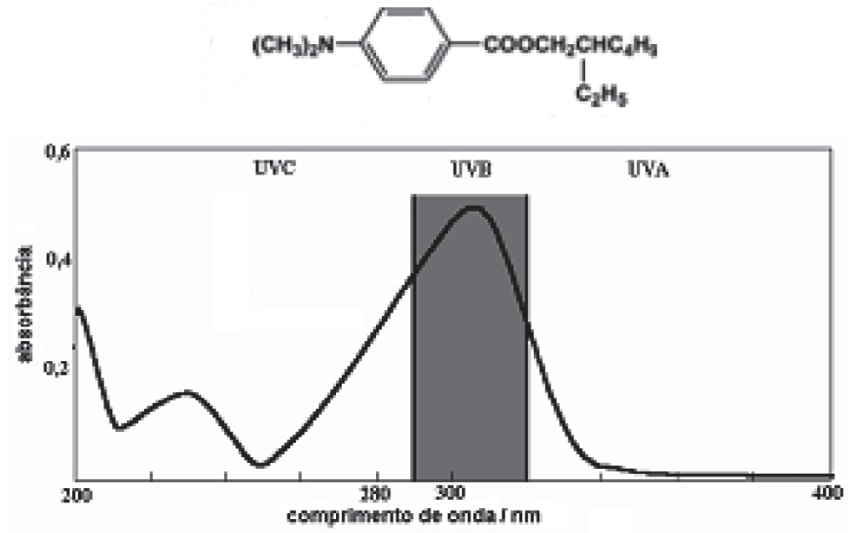

Figura 2. Fórmula estrutural e espectro de absorção do filtro $p$ Metoxicinamato de 2 etil-hexila (OctildimetilPABA), 5,16 $\mathrm{mg} \mathrm{L}^{-1}$ em etanol. Adaptada da ref. 16
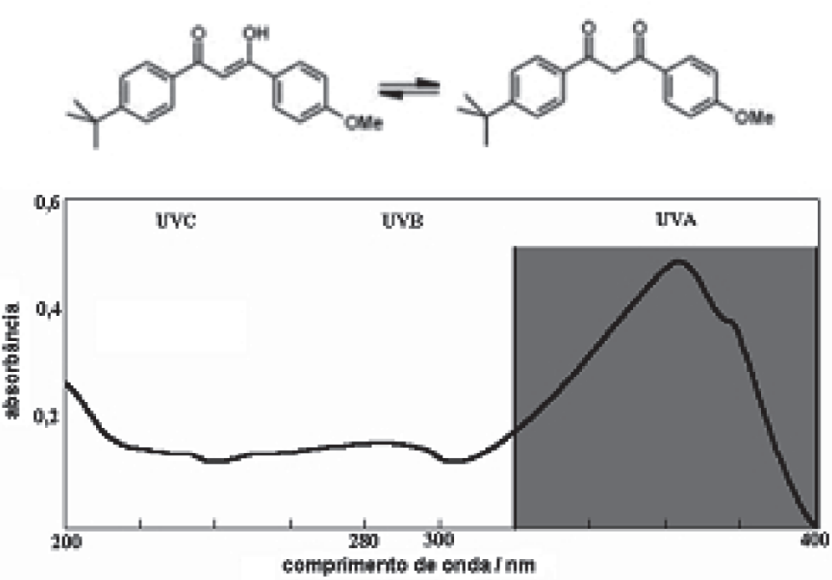

Figura 3. Fórmula estrutural e espectro de absorção do filtro 1-(4-tercbutilfenil)-3-(4-metoxifenil) propano-1,2-diona (Butil Metoxi-dibenzoilmetano), 5,20 $\mathrm{mg} \mathrm{L}^{-1}$ em etanol. Adaptada da ref. 16

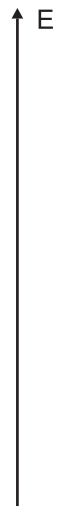

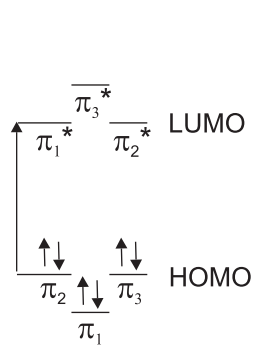

(a)

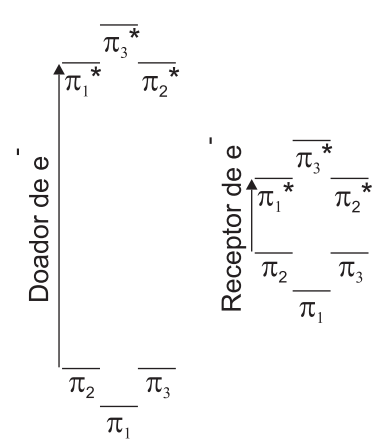

(b) (c)
Figura 4. Diagramas de orbitais moleculares: (a) benzeno simplificado, (b) $e(c)$ o mesmo com alterações pela adição de grupos doadores ou receptores de elétrons, respectivamente 
dibenzoil-metano tem-se apenas a presença do grupo receptor de elétrons $\mathrm{COCH}_{2} \mathrm{COHAr}$. Comparando o PABA com o OctildimetilPABA, apesar de termos a presença de grupos doadores de elétrons em ambos os casos, o grupo receptor de elétrons do OctildimetilPABA é mais eletronegativo, desestabilizando mais a estrutura do anel e diminuindo, assim, a diferença de energia entre os orbitais HOMO e LUMO. Como o comprimento de onda é inversamente proporcional à energia, a diminuição na diferença de energia leva a um aumento no comprimento de onda de absorção. Já para o caso do Butil Metoxi-dibenzoil-metano, além de não estar presente nenhum grupo doador de elétrons, o grupo $\mathrm{COCH}_{2} \mathrm{COHAr}$ é o grupo mais eletronegativo quando comparado com os grupos receptores de elétrons presentes no PABA e no OctidimetilPABA. Assim, o Butil Metoxi-dibenzoil-metano apresenta a menor diferença de energia entre os orbitais HOMO e LUMO e, como conseqüência, sua banda de absorção é a que ocorre em maiores comprimentos de onda, região UVA.

Como os filtros solares absorvem apenas parte da região do ultravioleta (UVA ou UVB), para se ter uma proteção completa deve-se fazer uma combinação entre estes filtros. Por outro lado, a combinação de diferentes tipos de filtros pode causar alto grau de irritabilidade quando aplicada à pele.

Especulação não comprovada, publicada em revista popular (Saúde é Vital, 2005, março, 43), discute o possível comportamento de alguns filtros solares orgânicos como hormônio sexual feminino. Essa hipótese partiu de um trabalho desenvolvido na Faculdade de Farmácia da Universidade de São Paulo, que tabulou os resultados de vários testes realizados em institutos de pesquisa no Japão, Estados Unidos e Suíça. A partir destes dados, é informado que os filtros orgânicos podem penetrar na pele, entrar na circulação sangüínea e difundir-se pelo corpo. Uma vez dentro do organismo agem como hormônio sexual feminino. Nas usuárias, este falso hormônio pode alterar o ciclo menstrual e causar males, como endometriose e crescimento anormal da parede uterina. Já nos homens pode causar uma diminuição na quantidade de espermatozóides e atrofia dos testículos. Em ambos os casos, não se descarta a hipótese de câncer. Nessa mesma reportagem um outro químico, da Associação Brasileira de Cosmetologia, diz não concordar com essa hipótese uma vez que resultados de experiências realizadas por todo o mundo apontam que os filtros orgânicos não oferecem perigo à saúde. Vale ressaltar que a reportagem não é publicação científica e não cita nenhuma referência científica sobre as afirmações que levaram a essas conclusões, portanto, trata-se apenas de especulações. Em trabalho recente, Janjua e colaboradore ${ }^{20}$ estudaram, a partir de experiências in vivo, a permeação dos filtros orgânicos 3-(4-metilbenzilideno), benzofenona 3 e octilmetoxicinamato na pele e seus efeitos nos níveis dos hormônios reprodutivos em seres humanos. Neste trabalho, concluiu-se que há uma penetração substancial destes filtros para o interior do nosso organismo. Após aplicação destes filtros, os mesmos foram detectados tanto na urina quanto no sangue dos voluntários. Porém, nenhuma alteração nos níveis do hormônio sexual feminino foi observada ${ }^{20}$ dentro do tempo fixado para controle.

Uma nova tecnologia promete ser solução para contornar o problema da penetração dos filtros orgânicos para o interior do organismo: a utilização de esferas de silicone contendo os filtros solares. As estruturas de silicone devem dificultar a penetração das moléculas de filtros solares na pele.

\section{Filtros inorgânicos}

Os filtros solares inorgânicos são representados por dois óxidos, $\mathrm{ZnO}$ e $\mathrm{TiO}_{2}$. Estes filtros solares representam a forma mais segura e eficaz para proteger a pele ${ }^{14}$, pois apresentam baixo potencial de irritação, sendo inclusive, os filtros solares recomendados no preparo de fotoprotetores para uso infantil e pessoas com peles sensíveis.

Óxido de zinco e dióxido de titânio são materiais semicondutores. Os mecanismos de absorção e de desativação envolvem transições entre bandas de valência e de condução do sólido.

Nos filtros inorgânicos, os processos de proteção envolvidos são diferentes daqueles das moléculas orgânicas. Vale ressaltar que os filtros inorgânicos são constituídos de partículas, de preferência com tamanhos da ordem da radiação que se quer espalhar. Por tratar-se de partículas, os filtros inorgânicos com tamanhos adequados de partículas além de absorção, apresentam espalhamento da luz UV.

Os óxidos usados como filtros solares quando incorporados às formulações ficam suspensos, sendo o tamanho das partículas do óxido de suma importância não apenas na eficácia do protetor solar como também na aparência cosmética do produto ${ }^{21}$. Um ponto negativo na utilização deste tipo de filtro solar é a tendência em deixar uma película branca sobre a pele, que pode ser esteticamente desagradável.

Uma inovação recente na tecnologia de filtros inorgânicos criou versões micro-particuladas destes óxidos. As partículas são reduzidas, durante o processo de obtenção, a dimensões tais que não absorvam nem espalhem radiação visível, mas absorvam e espalhem a radiação $U^{14}$. Essas versões microparticuladas, também chamadas pigmentos microfinos, representam um grande avanço, pois não deixam película perceptível sobre a pele. Nestas versões o tamanho de partículas está na faixa de 70 a $200 \mathrm{~nm}$.

O espalhamento máximo da luz ocorre na presença de partículas com diâmetro aproximadamente igual ao comprimento de onda $(\lambda)$ da luz incidente. Para não ocorrer a formação da película branca sobre a pele, o tamanho de partículas não pode ser da mesma ordem de grandeza do comprimento de onda da faixa da radiação visível, assim as partículas devem ser menores que $400 \mathrm{~nm}$.

Um dos tipos de espalhamento que pode ocorrer é o Rayleigh. A relação entre este espalhamento, tamanho de partícula e comprimento de onda da luz incidente é expressa como na Equação 1

$I_{R}=\frac{16 \pi^{4} R^{6}}{r^{2} \lambda^{4}}\left(\frac{n_{1}{ }^{2}-n_{2}{ }^{2}}{n_{1}{ }^{2}+2 n_{2}{ }^{2}}\right)^{2}$

onde $\mathrm{I}_{R}=$ intensidade do espalhamento; $\mathrm{R}=$ raio da partícula; $\lambda=$ comprimento de onda da luz incidente; $r$ = distância entre amostra e detector; $n_{1}=$ índice de refração da partícula e $n_{2}=$ índice de refração do meio.

Desta forma, a intensidade do espalhamento depende do comprimento de onda e é proporcional ao raio da partícula.

Podem ocorrer algumas interações não muito favoráveis associadas ao uso dos filtros solares inorgânicos. Os pigmentos microfinos precisam estar adequadamente dispersos no veículo, normalmente uma emulsão, para que se tenha eficácia. A má dispersão irá reduzir o desempenho do produto. Pigmentos microfinos também precisam ser mantidos em suspensão, de modo que não ocorra aglomeração das partículas, pois o desempenho final do produto diminuirá ${ }^{22}$ se, com o passar do tempo ocorrer coalescência e formação de agregados maiores. Outro ponto importantíssimo que deve ser considerado na utilização de micro partículas diz respeito ao $\mathrm{pH}$. Caso o pH da emulsão utilizada como veículo se iguale ao $\mathrm{pH}$ do ponto isoelétrico (PI), $\mathrm{pH}$ no qual a superfície do sólido passa a ter carga zero, as micro partículas irão coalescer ${ }^{22}$. O PI de um pigmento microfino varia, dependendo do tratamento dado à sua superfície. 
Vários são os métodos de obtenção de óxidos com controle de tamanho de partículas. $\mathrm{O} \mathrm{ZnO}$, por ex., pode ser obtido pelos métodos Pechini $^{23}$, sol gel ${ }^{24}$, precipitação homogênea ${ }^{25}$ entre outros, com características peculiares dependentes do método e das condições envolvidas nas etapas de cada um deles.

\section{FORMULAÇÕES DE PROTETORES SOLARES}

Para disponibilizar um filtro solar ao consumidor é necessário que o mesmo esteja incorporado a um veículo. A esta associação filtro solar/veículo denomina-se protetor solar ou fotoprotetor. Algumas características são exigidas para que os protetores solares sejam comercializados. Além de química, fotoquímica e termicamente inertes os protetores devem apresentar características como ser atóxico; não ser sensibilizante, irritante ou mutagênico; não ser volátil; possuir características solúveis apropriadas; não ser absorvido pela pele; não alterar sua cor; não manchar a pele e vestimentas; ser incolor; ser compatível com a formulação e material de acondicionamento e, ser estável no produto final.

Para preparar um protetor solar é necessária a presença de dois componentes básicos: os ingredientes ativos (filtros orgânicos e/ ou inorgânicos) e os veículos. Diversos são os veículos possíveis a serem utilizados no preparo de protetores solares, envolvendo desde simples soluções até estruturas mais complexas como emulsões. Os principais veículos empregados em preparações fotoprotetoras podem ser:

\section{Loções hidro-alcoólicas}

Compostas principalmente de água e álcool, são fáceis de espalhar na pele e evaporam rapidamente. Seu emprego tem sido questionado em razão dos baixos níveis de proteção obtidos. Além disso, o efeito deletério do álcool etílico sobre a pele tem sido questionado.

\section{Cremes e loções emulsionadas}

As emulsões constituem de longe o melhor veículo para os filtros solares ${ }^{26}$. Sendo constituídas de componentes tanto apolares (lipossolúveis) quanto polares (hidrossolúveis), podem carregar em sua estrutura tanto filtros hidrossolúveis quanto lipossolúveis, fato bastante saudável do ponto de vista da proteção. Tais sistemas podem ser O/A (óleo em água) ou A/O (água em óleo), características que também podem conduzir a preparações mais ou menos protetoras. As emulsões A/O são as mais adequadas para a proteção da pele, porém apresentam elevado caráter graxo ou gorduroso, com conseqüente desconforto para o usuário. Em razão ao exposto, as emulsões $\mathrm{O} / \mathrm{A}$ constituem os sistemas mais empregados e garantem adequada proteção com um sensorial mais confortável ao usuário.

\section{Géis}

São os veículos obtidos através de um espessante hidrofílico. Independentemente da origem do espessante, sejam eles naturais (gomas, alginatos) ou sintéticos (polímeros e copolímeros de acrilamida), os géis resultantes geralmente não oferecem os mesmos níveis de proteção que as emulsões. Além disso, para manter a transparência característica deste grupo de preparações existe a necessidade dos filtros solares serem hidrossolúveis. Como somente se conseguem altos níveis de proteção através da mistura de filtros e sendo estes, em sua grande maioria, lipossolúveis, a obtenção de géis transparentes é uma tarefa técnica extremamente delicada e pode envolver a inclusão de solventes nem sempre desejados, como é o caso do álcool etílico. Na preparação de géis fotoprotetores também se deve evitar a presença de filtros inorgânicos. Mesmo sendo microparticulado, os filtros inorgânicos oferecem ao gel, na melhor das hipóteses, aspecto opaco e, na maioria das vezes, resultam em aglomerados visíveis aos olhos do consumidor. O problema destas preparações não se resume apenas ao aspecto estético, mas, fundamentalmente, aos baixos níveis de proteção oferecidos. A presença de aglomerados no protetor levará à formação de uma película não homogênea em toda a extensão da pele, fato este que comprometerá sensivelmente o nível da proteção.

\section{FATOR DE PROTEÇÃO SOLAR}

A eficácia de um protetor solar é medida em função de seu fator de proteção solar (FPS), o qual indica quantas vezes o tempo de exposição ao sol, sem o risco de eritema, pode ser aumentado com o uso do protetor $^{27}$. Considerando, por ex., as mesmas localizações geográficas, estação do ano, condições climáticas e período do dia, uma pessoa de pele clara que pode ficar 20 min exposta ao sol sem protetor solar, poderá ficar $300 \mathrm{~min}$ exposta ao sol com um protetor de FPS $=15$, pois $20 \times 15=300$. Quanto maior o FPS maior será a proteção, ou seja, maior será o tempo que a pele ficará protegida frente à radiação UVB. Ressalta-se que o FPS é definido em função da radiação UVB causadora de eritemas.

$\mathrm{O}$ valor do FPS é calculado através da Equação 2

$F P S=\frac{D M E(\text { pele com } \text { proteção })}{D M E(\text { pele sem proteção })}$

onde DME = dose mínima eritematosa, ou seja, dose mínima necessária para ocorrer o eritema ${ }^{27}$.

Para a medida do FPS deve ser dada atenção especial à necessidade da aplicação correta do produto sobre a pele. Segundo Diffey $^{28}$, o padrão quantitativo de protetor solar por unidade de pele necessária para medir o FPS em humanos é $2 \mathrm{mg} / \mathrm{cm}^{2}$. Assim, a cada aplicação deverá ser usada a quantidade de 30 a $40 \mathrm{~g}$ do produto por um indivíduo adulto, de tamanho e peso normais. Estudos mostraram também que se aplicam normalmente dois terços do protetor com filtro inorgânico quando comparado aos protetores com filtros orgânicos, devido ao fato de os protetores solares à base de filtros inorgânicos serem mais difíceis de espalhar na pele ${ }^{15}$. Considerações deste tipo, reforçadas por alguns estudos realizados com o consumidor, indicam que o FPS obtido sem seguir o procedimento quantitativo citado acima resulta em valores que podem chegar a um terço do valor proposto ${ }^{29}$.

A determinação do FPS de um protetor solar é feita com testes in vivo. Alguns testes in vitro já foram propostos para auxiliar na

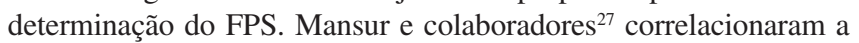
determinação do FPS em seres vivos e por espectrofotometria. Para obter os dados por espectrofotometria, os protetores solares foram dissolvidos em álcool na concentração de $0,2 \mu \mathrm{L} / \mathrm{mL}$, e os espectros de absorção medidos. Para a obtenção do FPS foi utilizada a Equação 3

FPS espectrofotométrico $=F C \cdot \sum_{290}^{320} E E(\lambda) \cdot I(\lambda) \cdot A b s(\lambda)$

onde $\mathrm{FC}=$ fator de correção $(=10)$ determinado de acordo com dois protetores solares de FPS conhecidos, de tal forma que um creme contendo $8 \%$ de homossalato desse 4 de $\operatorname{FPS}$; $\operatorname{EE}(\lambda)=$ efeito eritemogênico da radiação de comprimento de onda $\lambda$; $\mathrm{I}(\lambda)=$ intensidade do sol no comprimento de onda $\lambda$ e $\operatorname{Abs}(\lambda)=$ absorbância da solução no comprimento de onda $\lambda$.

Os resultados in vivo e in vitro (espectrofotometria) apresentaram boa correlação para os protetores com filtros orgânicos. Se- 
gundo os autores ${ }^{27}$, não há maneira mais precisa de se avaliar um protetor solar que testes em voluntários humanos, sob luz natural do sol. Porém, o método in vitro por espectrofotometria tem grande aplicação na previsão do FPS antes de se realizarem testes em seres humanos, reduzindo assim os riscos de queimaduras nos voluntários submetidos aos testes in vivo.

\section{CONSIDERAÇÕES FINAIS}

A Química tem um papel fundamental na formulação de protetores solares. O grau de proteção atingido pelos protetores pode estar diretamente associado ao maior conhecimento das estruturas com capacidade de absorver e/ou dispersar a radiação solar e de como essas estruturas se comportam frente a um determinado veículo, ou seja, suas interações e modificações espectrais. As mesmas concentrações de filtro solar incorporadas a diferentes tipos de veículos oferecerão diferentes FPS. O conhecimento das estruturas e das possíveis interações com os diferentes veículos ou matérias-primas propostas para estes veículos são de fundamental importância para o sucesso dos resultados. Porém, pouco se discute e pouco se propaga sobre a necessidade da aplicação correta do produto sobre a pele, tanto do ponto de vista qualitativo como quantitativo.

Conforme exposto, pode-se concluir que a indústria de protetores solares requer grande interdisciplinaridade. O caminho percorrido desde a elaboração do protetor até a sua aprovação para ser lançado no mercado requer o trabalho de especialistas de diferentes áreas. Químicos, físicos, biólogos, farmacêuticos, e, no extremo do processo, médicos, todos em conjunto, em um trabalho minucioso de entendimento, elaboração e orientação, poderão garantir a adequada proteção da pele frente aos indesejáveis efeitos da radiação ultravioleta.

\section{AGRADECIMENTOS}

À FUNDUNESP e ao CNPq pelo apoio financeiro. J. Flor agradece à CAPES pela bolsa concedida. Os autores também agradecem à assessoria desta publicação pelas valiosas sugestões.

\section{REFERÊNCIAS}

1. Dossiê especial sobre o sol; Cosméticos e Perfumes 2003, 27, 29.

2. De Paola, M. V. R. V.; Ribeiro, M. E.; Cosmet. Toil. (Ed. Port.) 1998, 10, 41.
3. Osterwalder, U.; Luther, H.; Herzog, B.; Cosmet. Toil. (Ed. Port.) 2000, 12,52 .

4. Thomas, M.; Ultraviolet and Visible Spectroscopy, $2^{\text {nd }}$ ed., Wiley: New York, 2000.

5. Ruvolo Júnior, E. C.; Cosméticos On Line 1997, 19, 37.

6. Steiner, D.; Cosmet. Toil. (Ed. Port.) 1995, 10, 29.

7. Streilein, J. W.; Taylor, J. R.; Vincek, V.; Kurimoto, I.; Shimizu, T.; Tié, C.; Coulomb, C.; Immunol. Today 1994, 15, 174.

8. Roy, C. R.; Gies, H. P.; Toomey, S.; J. Photochem. Photobiol. 1995, 31, 21.

9. Giles, G.; Report of the National health and medical research council, Australian Government Priting Service, Canberra, 1989, p. 82-95, apud Roy, C. R.; Gies, H. P.; Toomey, S.; J. Photochem. Photobiol. 1995, 31, 21.

10. Marks, R. Report of the National health and medical research council, Australian Government Priting Service, Canberra, 1989, p. 70-81, apud Roy, C. R.; Gies, H. P.; Toomey, S.; J. Photochem. Photobiol. 1995, 31, 21.

11. Taylor, C. R.; Stern, S.; Leyden, J. J.; Gilchrest, B. A.; J. Am. Acad. Dermatol. 1990, 22, 1.

12. Ziegler, A.; Jonason, A. S.; Leffeti, D. J.; Simon, J. A.; Sharma, H. W.; Kimmelmann, J.; Remington, L.; Jacks, T.; Brash, D. A.; Nature 1994, 372, 773.

13. Ananthaswsmy, H. N.; Loughlin, S. M.; Cox, P.; Evans, R. L.; Ullrich, S. E.; Kripke, M. L.; Nat. Med. 1997, 3, 510.

14. Schueller, R.; Romanowski, P.; Cosmet. Toil. (Ed. Port.) 2000, 12, 60.

15. Diffey, B. L.; Grice, J.; Br. J. Dermatol. 1997, 137, 103.

16. Enciclopédia de Absorvedores de UV para Produtos com Filtro Solar; Cosmet. Toil. (Ed. Port.) 1995, 7, 47.

17. Huheey, J. E.; Keiter, E. A.; Keiter, R. L.; Inorganic Chemistry: principles of structure and reactivity, $5^{\text {th }}$ ed., Harper Collins College: New York, 1993.

18. Santos Filho, P. F.; Estrutura Atômica \& Ligação Química, $1^{\mathrm{a}}$ ed., Ed. da UNICAMP: Campinas, 1999.

19. Gillam, A. E.; Stern, E. S.; An Introduction to Eletronic Absorption Spectroscopy, $2^{\text {nd }}$ ed., Edward Arnold: London, 1957.

20. Janjua, N. R.; Mogensen, B.; Anderson, A. M.; Petersen, J. H.; Henriksen, M.; Skakkebaek, N. E.; Wulf, H. C.; The Journal of Investigative Dermatology 2004, 123, 57.

21. De Paola, M. V. R. V.; Cosmet. Toil. (Ed. Port.) 2001, 13, 74.

22. Johncock, W.; Cosmet. Toil. (Ed. Port.) 2000, 12, 40.

23. Lima, S. A. M.; Sigoli, F. A.; Davolos, M. R.; J. Alloys Compd. 2002, 344, 280.

24. Flor, J.; Lima, S. A. M.; Davolos, M. R.; Progr. Colloid Polym. Sci.. 2004, $128,239$.

25. Sigoli, F. A.; Pires, A. M.; Stucchi, E. B.; Jafelicci Jr., M.; Davolos, M. R.; Quim. Nova 2000, 23, 627.

26. Lowe, N. J.; Shaath, N.; SUNSCREENS Development, Evaluation and Regulatory Aspects, $1^{\text {st }}$ ed., Marcel Dekker: New York, 1990.

27. Mansur, J. S.; Breder, M. N. R.; Mansur, M. C. A.; Azulay, R .D.; An. Bras. Dermatol. 1986, 61, 167.

28. Diffey, B. L.; Sunscreens, suntans and skin cancer 1996, 313, 942.

29. Autier, P.; Boniol, M.; Severi, G.; Br. J. Dermatol. 2001, 144, 288. 